\title{
Sparganosis Presenting as Pericardial Effusion and Lung Lesions
}

\author{
Xueying Chen ${ }^{1}$, Jin Bai ${ }^{1}$, Jingfeng Wang ${ }^{1}$, Kuan Cheng ${ }^{1}$, Chunmei Shen ${ }^{2}$, Haohua Yao ${ }^{3}$, \\ Bin Tang ${ }^{1}$ and Juying Qian ${ }^{1}$
}

\begin{abstract}
We herein report a rare form of sparganosis in a 29-year-old man presenting with pericardial effusion and lung lesions. The diagnosis was confirmed by the patient's history of eating inadequately cooked snake, significant elevated eosinophils in the peripheral blood and pericardial effusion, and marked positive reactions against Sparganum mansoni antigen in the serum. After two consecutive doses of praziquantel treatment, the patient's symptoms and laboratory and imaging findings were improved. Both specific antibody detection and follow-up of the patient's eosinophils, serum antibody, and imaging changes are important for sparganosis diagnosis, particularly in cases without a subcutaneous lump or mass.
\end{abstract}

Key words: sparganosis, pericardial effusion, lung lesions

(Intern Med 54: 1135-1139, 2015)

(DOI: 10.2169/internalmedicine.54.3478)

\section{Introduction}

Sparganosis, caused by the plerocercoid of the tapeworm, has been reported sporadically around the world, especially in several Asian countries, including South Korea, Japan, Thailand, and China (1-4). Infection in humans occurs by drinking water contaminated with procercoid-infected copepods, ingesting raw or inadequately cooked flesh of frogs or snakes infected with spargana, or by placing poultices of frog or snake flesh or skin on the eyes or open wounds and other lesions.

The most common clinical manifestation of sparganosis is a subcutaneous lump or mass in the abdominal wall, scrotum, lower extremity, or chest wall. Sparganum mansoni can also invade muscle, intestines, breast tissue, eyes, spinal cord, brain and, rarely, the thoracic cavity, such as the lung (5), peritoneopleural cavity (6-13), and pericardium (14).

We herein report a rare form of human sparganosis that presented as pericardiopleural effusion and lung lesions without a subcutaneous mass or lump.

\section{Case Report}

A 29-year-old man was admitted to our hospital for progressive shortness of breath for two weeks in the middle of December, 2011. Approximately 3 weeks before admission, the man had a fever of $38^{\circ} \mathrm{C}$ and was relieved after two days of intravenous treatment with antibiotics. However, the patient felt a shortness of breath initially during exercise which gradually led to the onset of dyspnea while in the supine position. The symptom could be abated by sitting up or while in the lateral position. The patient's past history was unremarkable except he reported eating inadequately cooked snake 6 weeks prior to admission.

The patient's physical findings were as follows: blood pressure, 120/88 $\mathrm{mmHg}$; heart rate, 110/min; respiratory rate, $20 / \mathrm{min}$; body temperature, $37.4^{\circ} \mathrm{C}$; jugular vein distention; enlarged cardiac dullness; and distant cardiac sound.

The initial laboratory test results were as follows: an increased white blood cell (WBC) count, eosinophil count, erythrocyte sedimentation rate (ESR), C-reactive protein (CRP) level, and total serum IgE level (Table 1). The results

\footnotetext{
${ }^{1}$ Shanghai Institution of Cardiovascular Disease, Department of Cardiology, Zhongshan Hospital, Fudan University, China, ${ }^{2}$ Department of Cardiology, Haimen Traditional Chinese Medicine Hospital, China and ${ }^{3}$ Department of Echocardiography, Zhongshan Hospital, Fudan University, China

Received for publication June 18, 2014; Accepted for publication September 5, 2014

Correspondence to Dr. Juying Qian, qian.juying@zs-hospital.sh.cn
} 
Table 1. Laboratory Data of the Blood

\begin{tabular}{|c|c|c|c|c|}
\hline Variables & On Admission & $\begin{array}{l}\text { On Day } 2 \\
\text { after } \\
\text { Admission }\end{array}$ & $\begin{array}{l}\text { On Day } 4 \\
\text { after } \\
\text { Admission }\end{array}$ & $\begin{array}{l}\text { Reference } \\
\text { Range }\end{array}$ \\
\hline $\begin{array}{l}\text { White blood cells } \\
\left(\times 10^{9} / \mathrm{L}\right)\end{array}$ & 10.77 & 11.64 & 11.65 & $4-10$ \\
\hline $\begin{array}{l}\text { Eosinophil Count } \\
(\%)\end{array}$ & 11 & 18.9 & 30 & $0.5-5$ \\
\hline $\begin{array}{l}\text { Eosinophils } \\
\left(\times 10^{9} / \mathrm{L}\right)\end{array}$ & 1.18 & 2.20 & 3.50 & $0.02-0.5$ \\
\hline $\begin{array}{l}\text { C-reactive protein } \\
(\mathrm{mg} / \mathrm{dL})\end{array}$ & 6.1 & 26.8 & N/A & $0-3$ \\
\hline $\begin{array}{l}\text { Total serum IgE } \\
(\mathrm{IU} / \mathrm{mL})\end{array}$ & 258 & 406 & N/A & $<200$ \\
\hline $\begin{array}{l}\text { Lactate } \\
\text { dehydrogenase (U/L) }\end{array}$ & 241 & 254 & N/A & $109-245$ \\
\hline
\end{tabular}
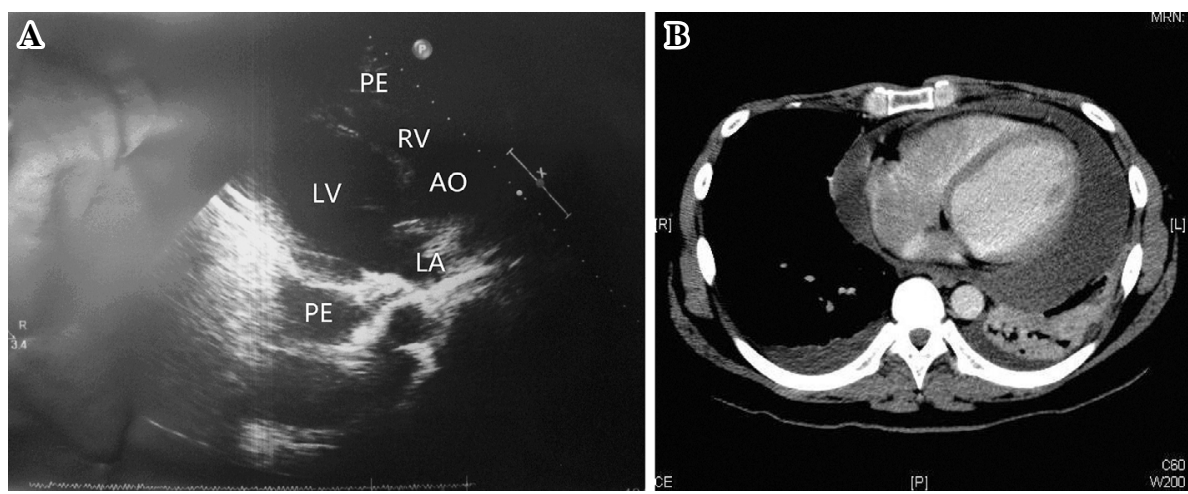

Figure 1. Images obtained at the time of admission. (A) Echocardiogram demonstrated pericardial effusion with a maximal depth of $36 \mathrm{~mm}$ without hemodynamic significance. (B) Chest CT showed a large amount of pericardial effusion and a minimal amount of pleural effusion and atelectasis in the left inferior lung lobe. PE: pericardial effusion, LA: left atrium, LV: left ventricle, RV: right ventricle, AO: aortic root

Table 2. Laboratory Data of the Pericardial Effusion

\begin{tabular}{|c|c|c|c|}
\hline Variables & On Admission & $\begin{array}{l}\text { On Day } 2 \text { after } \\
\text { Admission }\end{array}$ & $\begin{array}{l}\text { Reference } \\
\text { Range }\end{array}$ \\
\hline Color & Bloody & $\mathrm{N} / \mathrm{A}$ & $\mathrm{N} / \mathrm{A}$ \\
\hline Rivalta's reaction & Positive & $\mathrm{N} / \mathrm{A}$ & $\mathrm{N} / \mathrm{A}$ \\
\hline Red blood cells $\left(/ \mathrm{mm}^{3}\right)$ & 25,416 & $\mathrm{~N} / \mathrm{A}$ & $\mathrm{N} / \mathrm{A}$ \\
\hline White blood cells $\left(/ \mathrm{mm}^{3}\right)$ & 1,512 & $\mathrm{~N} / \mathrm{A}$ & $\mathrm{N} / \mathrm{A}$ \\
\hline Lymphocytes $(\%)$ & 38 & $\mathrm{~N} / \mathrm{A}$ & N/A \\
\hline Neutrophils $(\%)$ & 51 & $\mathrm{~N} / \mathrm{A}$ & N/A \\
\hline Eosinophils (\%) & 11 & $\mathrm{~N} / \mathrm{A}$ & N/A \\
\hline Specific gravity & 1.022 & $\mathrm{~N} / \mathrm{A}$ & $\mathrm{N} / \mathrm{A}$ \\
\hline Lactate dehydrogenase (U/L) & 1,150 & 1,322 & N/A \\
\hline Total protein $(\mathrm{g} / \mathrm{L})$ & 47.06 & 46.16 & N/A \\
\hline Sodium $(\mathrm{mmol} / \mathrm{L})$ & 141 & 141 & N/A \\
\hline Potassium $(\mathrm{mmol} / \mathrm{L})$ & 3.7 & 3.9 & N/A \\
\hline Chlorine $(\mathrm{mmol} / \mathrm{L})$ & 103 & 104 & $\mathrm{~N} / \mathrm{A}$ \\
\hline Glucose $(\mathrm{mmol} / \mathrm{L})$ & 6.7 & 6.7 & N/A \\
\hline Adenosine deaminase $(\mathrm{U} / \mathrm{L})$ & 48 & 51 & $<45$ \\
\hline
\end{tabular}

N/A: not available

of urine and stool routine tests were normal, as were liver and renal function, electrolyte, thyroid function, tumor markers (including AFP, CEA, PSA, CA 19-9, CA 15-3, CA 242, NSE, and cyfra 21-1), cardiac troponia T (cTnT), cre- atinine kinase, $\mathrm{MB}$ isoenzyme (CK-MB), serum autoimmune antibodies [including rheumatoid factor, anti-nuclear antibody (ANA), ds-DNA, extractable nuclear antigen (ENA), anti-neutrophil cytoplasmic antibodies (ANCA), anti-mitochondrial antibody (AMA), anticardiolipin, cANCA, and p-ANCA], enterovirus RNA, and Coxsackie B virus IgM. The purified protein derivative (PPD) test was also negative.

Electrocardiography (ECG) showed sinus tachycardia with T wave flat in lead of II, III, AVF, and V1-6. Echocardiography demonstrated a pericardial effusion of maximal depth $36 \mathrm{~mm}$ without hemodynamic significance (Fig. 1A). Chest computed tomography (CT) also showed a large amount of pericardial effusion and a minimal amount of pleural effusion and atelectasis in the left inferior lung lobe (Fig. 1B).

The pericardial effusion was bloody in color, positive in Rivalta's reaction, and contained numerous red blood cells $\left(25,416 / \mathrm{mm}^{3}\right)$ and inflammatory cells $\left(1,512 / \mathrm{mm}^{3}, 38 \%\right.$ lymphocytes, $51 \%$ neutrophils, and $11 \%$ eosinophils). Protein and lactate dehydrogenase levels in the pericardial fluid and serum were $47.06 \mathrm{~g} / \mathrm{L}$ and $1,150 \mathrm{U} / \mathrm{L}$ and $73 \mathrm{~g} / \mathrm{L}$ and 241 $\mathrm{U} / \mathrm{L}$, respectively. Other pericardial effusion results were as 

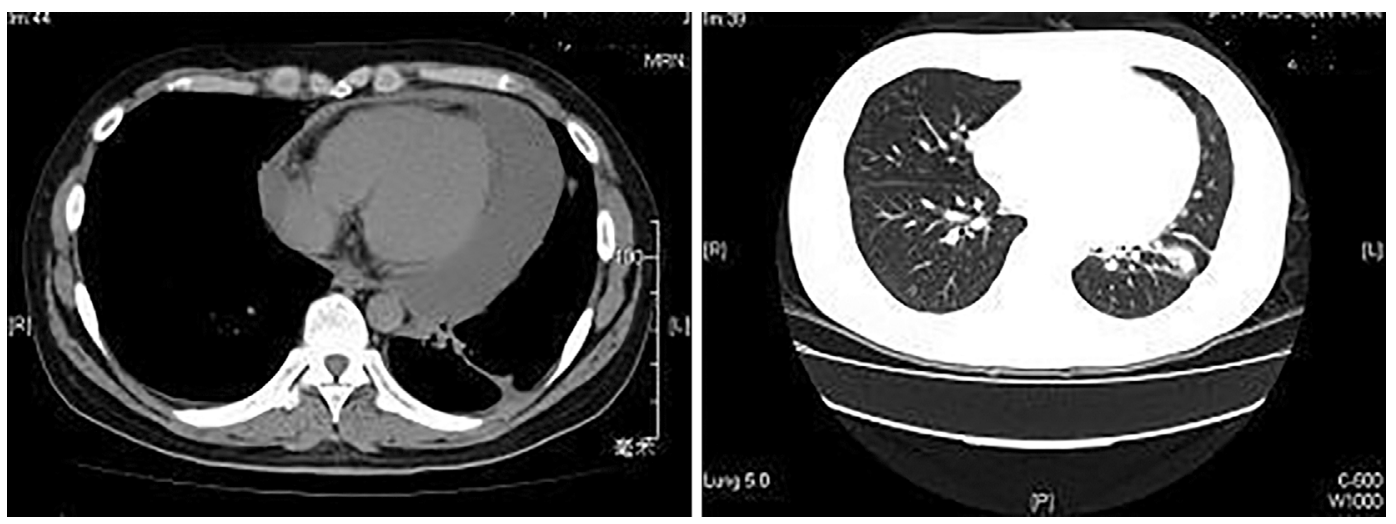

Figure 2. Chest CT obtained after pericardial effusion drainage $(-2,000 \mathrm{~mL})$ showed a medium amount of pericardial effusion, a minimal amount of pleural effusion, and multiple lesions in the left inferior lung lobe with high CT values.

follows: specific gravity, 1.022; glucose, $6.7 \mathrm{mmol} / \mathrm{L}$; sodium, $141 \mathrm{mmol} / \mathrm{L}$; chlorine, $103 \mathrm{mmol} / \mathrm{L}$; potassium, 3.7 $\mathrm{mmol} / \mathrm{L}$; and adenosine deaminase (ADA), $48 \mathrm{U} / \mathrm{L}$ (Table 2). Malignant cells were not detected by cytological examination. Cultures for Mycobacterium tuberculosis or other bacteria were negative. Follow-up chest CT after pericardial effusion drainage $(-2,000 \mathrm{~mL})$ showed a medium amount of pericardial effusion, a minimal amount of pleural effusion, and multiple lesions in the left inferior lung lobe with high CT values (Fig. 2).

We suspected a parasitic infection based on the elevated eosinophils in the peripheral blood and pericardial effusion. However, neither worms nor eggs were found in the patient's stool or pericardial effusion. His serum was therefore examined by Enzyme-linked immunosorbent assay (ELISA) to detect specific antibody against various parasite antigens including Clonorchis sinensis, Paragonimus westermani, Schistosoma, Echinococcus granulosus, Trichinella spiralis, Toxoplasma gondii, Angiostrongylus cantonensis, Filaria, Sparganum mansoni, and Cysticercus cellulosae. The patient's serum was positive for Sparganum mansoni antibodies.

Anti-Sparganum mansoni IgG of the patient's serum were determined using a commercially available ELISA kit (Kangbaide Biological Technology, Shenzhen, China, \#S.m 080910) as previously described $(14,15)$. Anti-Sparganumspecific $\mathrm{IgG}$ in the patient's serum was higher $(\mathrm{OD}=0.93 \pm$ $0.02)$ than the negative control level $(\mathrm{OD}=0.15 \pm 0.01)$. However, the ODs of the patient's serum IgG antibodies against the other parasites were similar to the negative controls.

Furthermore, fundus examination and head and abdomen CT showed no evidence of eye, brain, or abdomen involvement. As a result, the clinical diagnosis was Sparganosis mansoni infection. Because the left lower lung lesions were close to the diaphragm and ribs, it was hard to perform a transcutaneous lung biopsy or bronchoscopy to get a pathological diagnosis. We recommended a surgical resection of the lung, but the patient refused this suggestion.

The patient was therefore treated with praziquantel at 16.7 $\mathrm{mg} / \mathrm{kg} /$ day for 9 days in combination with dexamethasone
(0.75 $\mathrm{mg}$ tid) and moxifloxacin $(0.4 \mathrm{~g} /$ day) to prevent immunoreaction and bacterial infection. The patient was discharged after 9 days of treatment with a symptomatic improvement.

Approximately 10 days after discharge, the patient's blood examination showed a WBC count of $11.6 \times 10^{9} / \mathrm{L}$ with $12.7 \%$ eosinophils $\left(1.47 \times 10^{9} / \mathrm{L}\right)$. The pericardial effusion decreased to less than $10 \mathrm{~mm}$ depth on echocardiography (Fig. 3A) and chest CT showed significantly decreased lung lesions (Fig. 3B).

Approximately 4 weeks later, the patient was treated with a second course of praziquantel $(50 \mathrm{mg} / \mathrm{kg} / \mathrm{day})$ for three days with dexamethasone $(0.75 \mathrm{mg}$ tid). His eosinophil count gradually returned to the normal range (Fig. 4). Approximately 6 weeks after the second course of praziquantel treatment, both the pericardial effusion and the lung lesions disappeared on chest CT (Fig. 5). The IgG antibody against Sparganum mansoni remained positive, but the serum OD was much lower than before (OD of the serum: $0.45 \pm 0.01$, OD of negative control: $0.13 \pm 0.02$ ).

After 2 years follow-up, the patient's eosinophil count, echocardiography, and chest CT all remained normal. Repeated ELISA showed the serum OD against Sparganum mansoni antigen was negative (OD of the serum: $0.21 \pm 0.02$, OD of negative control: $0.16 \pm 0.02$ ).

\section{Discussion}

In the present case, the patient suffered from progressive shortness of breath due to a large amount of pericardial effusion. Common causes of pericardial effusion are idiopathic, infection (bacterial, viral, fungal, or parasitic organisms), trauma, hemorrhage, cancer, radiation therapy, kidney failure, and autoimmune disorders (hypothyroidism, inflammatory bowel disease, and rheumatoid arthritis). Parasitic infection presenting as pericardial effusion and lung lesions in this patient was confirmed by the history of eating inadequately cooked snake, significant elevated eosinophils in the peripheral blood and pericardial effusion, marked positive reaction against Sparganum mansoni antigen in the serum, 

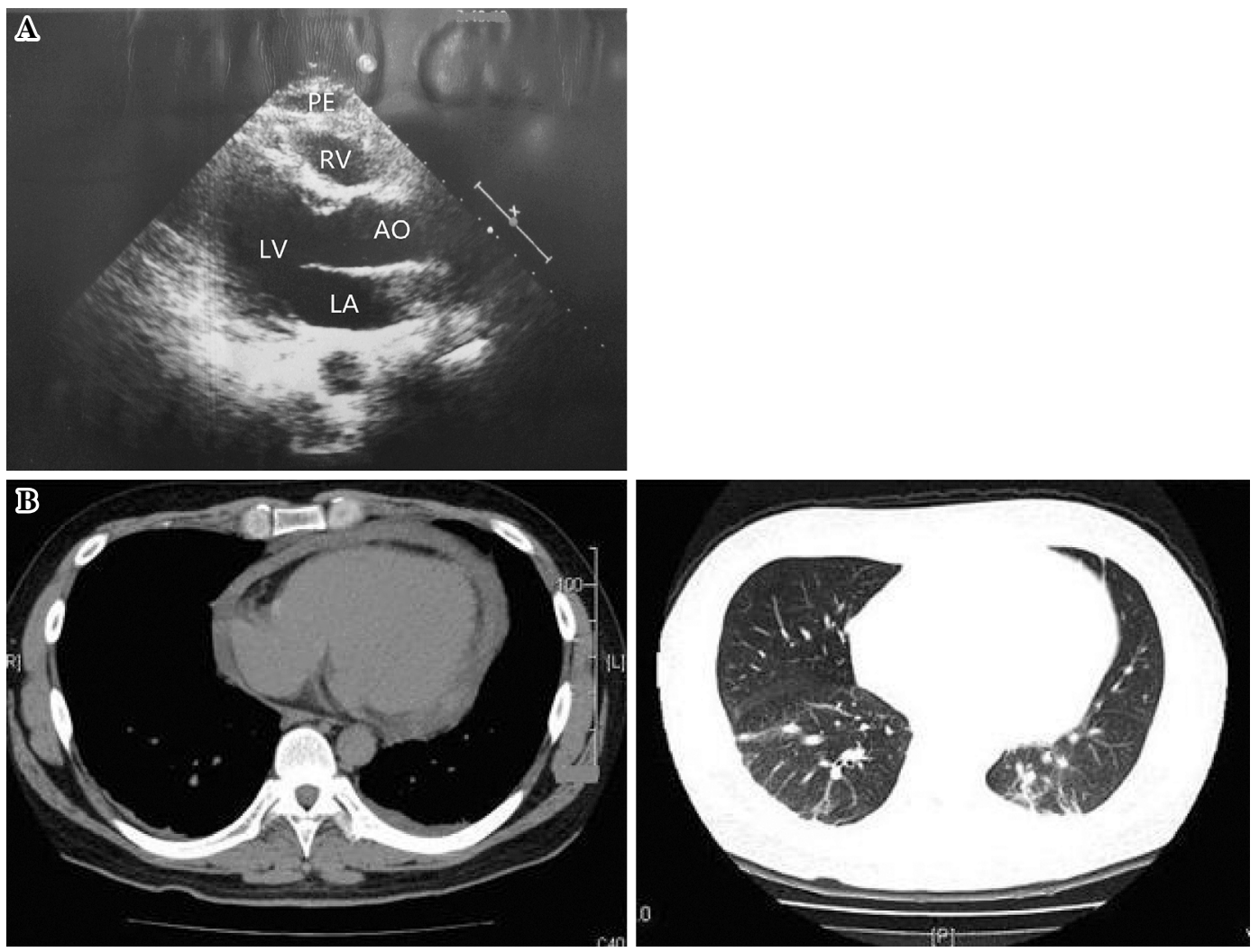

Figure 3. Images obtained 10 days after the first course of praziquantel treatment. (A) Echocardiogram showed a minimal amount of pericardial and pleural effusion. (B) Chest CT showed a minimal amount of pericardial and pleural effusion and lung lesions significantly decreased. PE: pericardial effusion, LA: left atrium, LV: left ventricle, RV: right ventricle, AO: aortic root

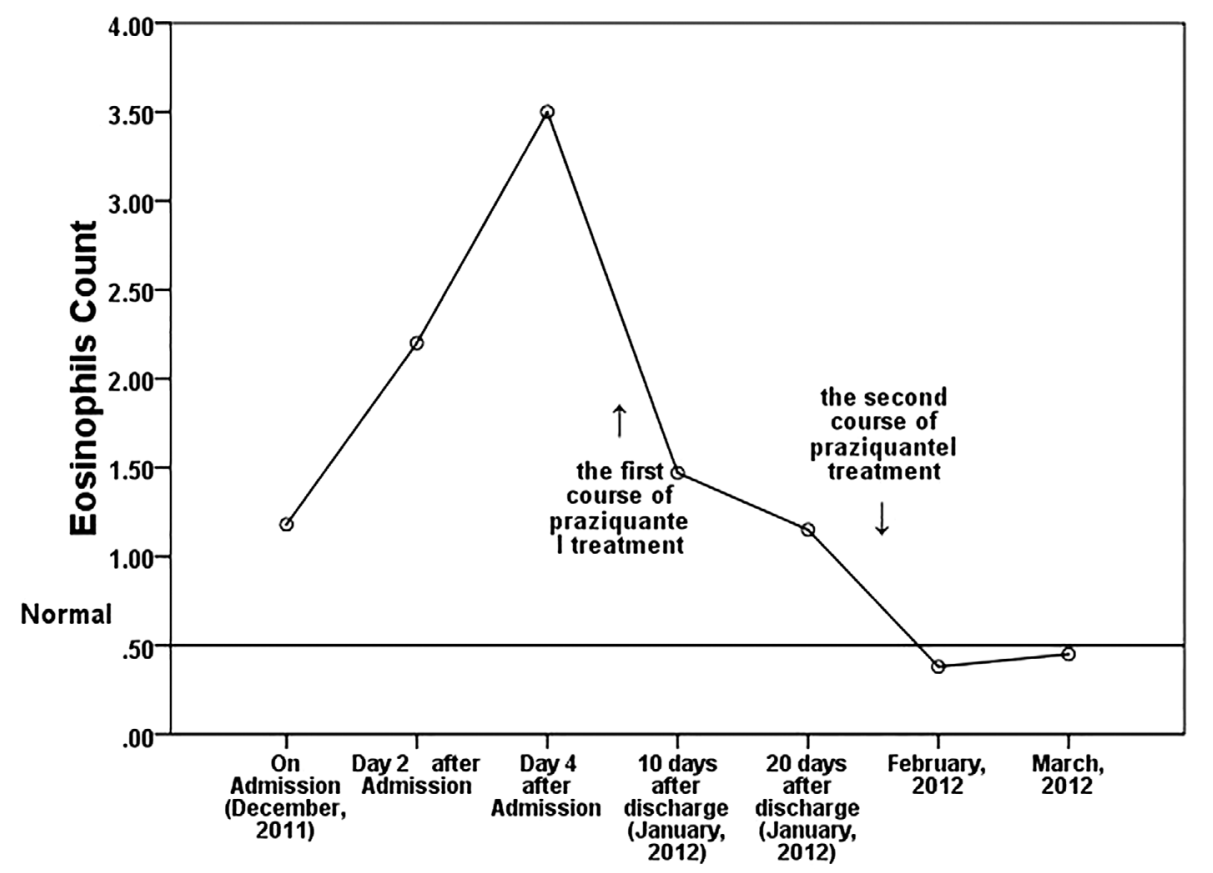

Figure 4. The eosinophil count gradually decreased to the normal range after two courses of praziquantel treatment.

and effective treatment with praziquantel.

Sparganosis is one of the common zoonoses in Asian countries. The first case of human sparganosis was reported in 1882 in Xiamen of Fujian Province, China. Currently, a total of more than 1,000 cases of human sparganosis have been reported in 25 provinces in mainland China (4, 16-18). 

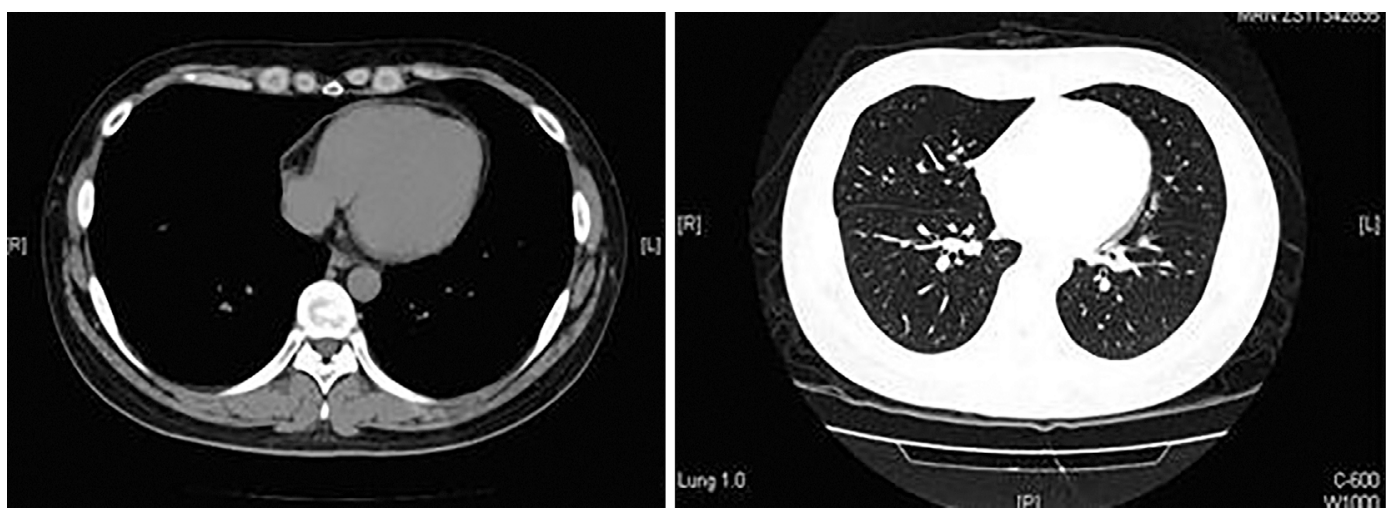

Figure 5. Chest CT obtained a month and a half after the second course of praziquantel treatment showed the pericardial effusion and lung lesions had disappeared.

Human sparganosis manifests with various clinical symptoms which typically manifest as slowly growing and migratory subcutaneous nodules. The thoracic cavity is a rare site for the localization of this parasite in humans. To our knowledge, less than 20 cases of pleural sparganosis in Asia (7-13) and only 1 case of recurrent pericardial effusion and pleural effusion have been reported (14).

Regarding the route of infection to the thoracic cavity, it is proposed that the parasite penetrates across the intestinal wall and invades the thoracic cavity through the diaphragm. Although a diagnosis of human sparganosis is usually established based on pathologic examinations of such worms, in our case it was impossible to perform a pathologically diagnosis due to the location of the lesions and the patient's refusal to undergo surgery. Concerning the treatment, praziquantel has been reported to be effective for the treatment of sparganosis-related pleural effusion (7-9) and pericardial effusion (14), which was confirmed based on the effectiveness of the treatment of our patient in the present case.

Although sparganosis in the thoracic cavity is rather rare, this possibility must be considered in cases of significantly elevated eosinophil counts in both the peripheral blood and pericardial effusion. Specific antibody detection by ELISA is helpful for making a differential diagnosis. Moreover, follow-up of eosinophil counts, serum antibody levels, and imaging changes following chemotherapy is also important for diagnosis, especially in cases lacking of pathological examination. Concerning the treatment, we suggest that praziquantel is a good therapeutic option for pericardial effusion and lung lesions related to sparganosis.

The authors state that they have no Conflict of Interest (COI).

\section{References}

1. Shin EH, Guk SM, Kim HJ, Lee SH, Chai JY. Trends in parasitic diseases in the Republic of Korea. Trends Parasitol 24: 143-150,
2008.

2. Nithiuthaia S, Anantaphrutib MT, Waikagulb J, Gajadharc A. Waterborne zoonotic helminthiases. Vet Parasitol 126: 167-193, 2004.

3. Wiwanitkit V. A review of human sparganosis in Thailand. Int $J$ Infect Dis 9: 312-316, 2005.

4. Li MW, Song HQ, Li C, et al. Sparganosis in mainland China. Int J Infect Dis 15: e154-e156, 2011.

5. Iwatani K, Kubota I, Hirotsu Y, et al. Sparganum mansoni parasitic infection in the lung showing a nodule. Pathol Int 56: 674677, 2006.

6. Cho SY, Bae JH, Seo BS. Some aspects of human sparganosis in Korea. Korean J Parasitol 13: 60-77, 1975.

7. Tanaka S, Maruyama H, Ishiwata K, Nawa Y. A case report of pleural sparganosis. Parasitol Int 46: 73-75, 1997.

8. Ishii $\mathrm{H}$, Mukae $\mathrm{H}$, Inoue $\mathrm{Y}$, et al. A rare case of eosinophilic pleuritis due to sparganosis. Intern Med 40: 783-785, 2001.

9. Kamiya H, Shimizu H, Kobayashi N, Kudo K. A case of sparganosis with eosinophilic pleural effusion. Nihon Kokyuki Gakkai Zasshi 42: 1019-1023, 2004 (in Japanese, Abstract in English).

10. Shimada M, Matsumura K, Aoki Y, et al. Two cases of sparganosis having onsets of pleural effusion. Jpn J Parasitol 38: 145, 1989.

11. Yamasaki H, Araki K, Aoki T. Parasitic diseases examined during the past 16 years in the Department of Parasitology, Juntendo University School of Medicine. Juntendo Igaku (Juntendo Medical Journal) 40: 262-279, 1994.

12. Kim DH, Yi IH, Youn HC, et al. Pleural sparganosis: a case report. Korean J Thorac Cardiovasc Surg 39: 502-504, 2006 (in Korean, Abstract in English).

13. Koh TW, Lee JW, Sohn DS, et al. Empyema thoracis associated with sparganosis: a case report. Korean J Thorac Cardiovasc Surg 21: 761-765, 1988 (in Korean, Abstract in English).

14. Lee JH, Kim GH, Kim SM, et al. A case of sparganosis that presented as a recurrent pericardial effusion. Korean Circ J 41: 38-42, 2011.

15. Cui J, Li N, Wang ZQ, Jiang P, Lin XM. Serodiagnosis of experimental sparganum infections of mice and human sparganosis by ELISA using ES antigens of Spirometra mansoni spargana. Parasitol Res 108: 1551-1556, 2011.

16. Zhan XM. Human Parasitology. 1st ed. People's Medical Publishing House, Beijing, 2005: 156-159 (in Chinese).

17. Yin GR, Yang YB, Li PZ. Common food-borne parasitic diseases and their prevention and control in China. Chin J Dis Cont Prev 10: 400-402, 2006 (in Chinese).

18. Wang RH, Hu JF, Liu JF. Research progress in sparganosis. Bull Endemic Dis 20: 83-84, 2005 (in Chinese).

(C) 2015 The Japanese Society of Internal Medicine http://www.naika.or.jp/imonline/index.html 